\title{
Case of bilateral complete posterior dislocation of lens caused by elder abuse
}

This article was published in the following Dove Press journal:

Clinical Ophthalmology

16 February 2012

Number of times this article has been viewed

\author{
Tetsuya Mutoh ${ }^{1,2}$ \\ Thomas Tien ${ }^{2}$ \\ Megumi Horie' \\ Yukihiro Matsumoto' \\ Makoto Chikuda' \\ 'Department of Ophthalmology, \\ Dokkyo Medical University Koshigaya \\ Hospital, Koshigaya, Saitama, Japan; \\ ${ }^{2}$ Department of Ophthalmology, \\ Boston University School of Medicine, \\ Boston, MA, USA
}

Correspondence: Tetsuya Mutoh

Department of Ophthalmology, Dokkyo Medical University Koshigaya Hospital,

2-I-50, Minami-Koshigaya, Koshigaya,

Saitama 343-8555, Japan

Tel +8 I 48965 I I I I

Fax +8I 48965 II 27

Email mtetsuya@dokkyomed.ac.jp
Abstract: We report a case of bilateral complete dislocation of lenses into the vitreous cavities due to elder abuse in a patient with senile dementia. According to the patient's son, bilateral complete lens dislocation occurred after he hit his father in the head with socks in order to control his violent behavior. Although the patient was taken to our ophthalmological ward for a planned vitrectomy, restlessness and inability to remain in his room during the night led to his leaving the hospital. The patient has not returned but did receive a vitrectomy at another clinic. While the number of patients with senile dementia has dramatically increased, no specific remedy is currently available. When treating medical concerns of seniors with unknown backgrounds, elder abuse needs to be considered as a potential cause of such injuries.

Keywords: bilateral dislocation of lenses, elder abuse, senile dementia, vitrectomy

\section{Introduction}

Considering the recent increase in elder abuse by caregivers, especially among community-dwelling elderly, ${ }^{1}$ it is important to deal with elder abuse in Japan. This increase in elder abuse has been recognized not only in Japan but also in other countries, with the associated problems classified into four groups, ie, neglect, emotional abuse, physical abuse, and financial exploitation. ${ }^{2}$ Physical abuse is defined as acts of violence that cause pain, injury impairment, or disease, and involves behaviors such as hitting, slapping, and kicking. ${ }^{2}$ Studies of senile dementia have reported that in some cases, the physical abuse can become so severe that it leads to the death of the patient. ${ }^{3}$ In less severe cases, variable lesions may result, such as lens dislocation. ${ }^{4}$

The primary cause of complete lens dislocation is trauma, especially in cases with zonular weakness such as in Marfan syndrome or in pseudoexfoliation. ${ }^{5}$ Treatment of these cases over the past few years has typically included pars plana vitrectomy with lensectomy. ${ }^{5}$ However, to the best of our knowledge, there has only been one other reported case of bilateral complete lens dislocation due to domestic violence. ${ }^{6}$ In the current case report, we document bilateral complete dislocation of the lenses into the vitreous cavities of a patient who was being physically abused by his son.

\section{Case report}

A 75-year-old Japanese man with senile dementia was hit in the face with socks by his son on March 28, 2010 and taken to the hospital three days following the incident. The patient was diagnosed with bilateral complete dislocation of his lenses and was subsequently presented to Dokkyo Medical University Koshigaya Hospital. The patient sometimes acted violently. Initial examination of his right and left eyes determined the 
best corrected visual acuity to be $20 / 40(+15.00+1.50 \times 40)$ and 20/30 (+13.00 diopters), while his intraocular pressure was $16 \mathrm{mmHg}$ and $35 \mathrm{mmHg}$, respectively. The patient did not mention heart disease in his past medical history, and features characteristic of Marfan syndrome, such as long limbs, long and thin fingers, and electrocardiographic abnormalities, were not observed. The patient was observed to have two black eyes, but no fracture was found. Neither stromal atrophy on the surface of iris nor Sampaolesi's line was observed in the gonio. Subconjunctival orbital fat herniation was noted on the temporal side of the left eye. No lenses were observed in either of his eyes (Figures 1 and 2), and a subsequent postmydriatic examination determined that both of the lenses had been displaced into the vitreous cavities (Figures 3 and 4). Retinal concussion, choroidal rupture, and retinal detachment were not observed in the fundus. After scheduling the patient for vitrectomy and lensectomy procedures, the patient was admitted to the ophthalmological ward. However, due to problems with restlessness and wandering throughout the hospital during the night, the patient decided to leave the hospital the following morning. The patient never returned to our hospital, but a social worker informed us that the patient received bilateral vitrectomy at an outpatient clinic and recovered his visual acuity.

\section{Discussion}

Cases of complete bilateral lens dislocation due to eye trauma are very rare. To the best of our knowledge, the current case is the second reported in the world. In a similar study, a case in Thailand was reported in which bilateral anterior lens dislocation occurred by splashing of water. ${ }^{7}$

It has been reported that when patients with senile dementia are aggressive, their families respond aggressively

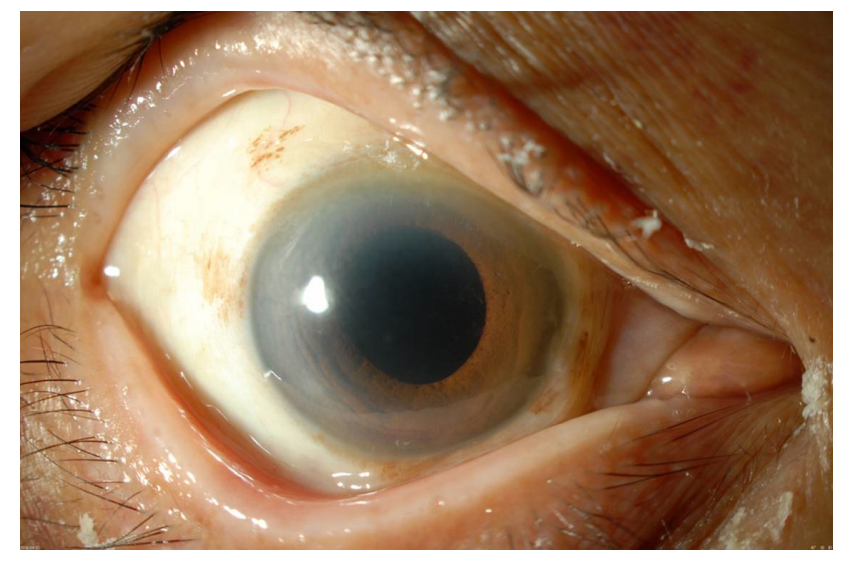

Figure I Preoperative anterior segment of the right eye. No lens is present.

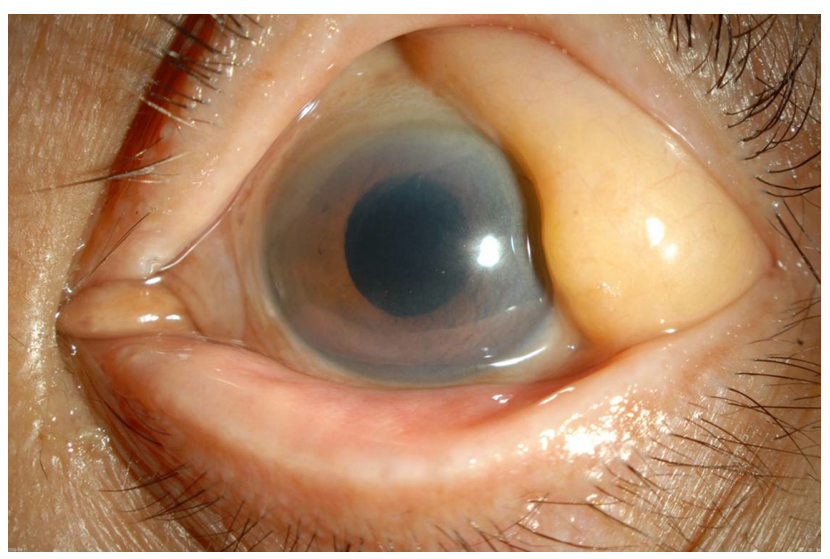

Figure 2 Preoperative anterior segment of the left eye. No lens is present.

as well. ${ }^{8}$ Aggressive behavior is a serious problem in the family-based care of patients with senile dementia, and it may occasionally be dangerous for the senile patient. ${ }^{9}$ In the current case, both the patient and his son appeared to have inflicted physical harm on each other. For instance, we observed multiple scratches on the arms and chest of the patient's son. The son reported that these scratches were made by his father, the senile patient. In response to this aggressive behavior, the son attempted to tame his father by hitting him with socks, an action we believe to have caused lens dislocation.

Until the late 1990 s violence within the family was typically a gender-related power issue of domestic violence, in which females were battered by their partners. ${ }^{10}$ However, in the last decade, the concept and understanding of violence within the family has been expanded to include all types of violence, such as child abuse and elder abuse. ${ }^{10}$ Patients who have been subjected to domestic violence often have eye traumas that include completely dislocated lenses, ${ }^{6}$ traumatic cataract ${ }^{11}$ retinal detachments, ${ }^{11}$ and orbital fractures. ${ }^{12}$ In

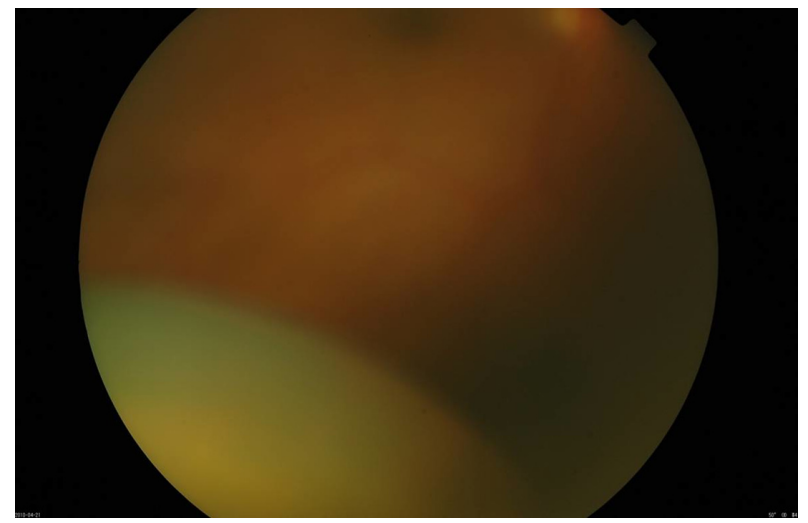

Figure 3 Preoperative ocular fundus examination of the right eye. The lens has been displaced into the vitreous cavity. 


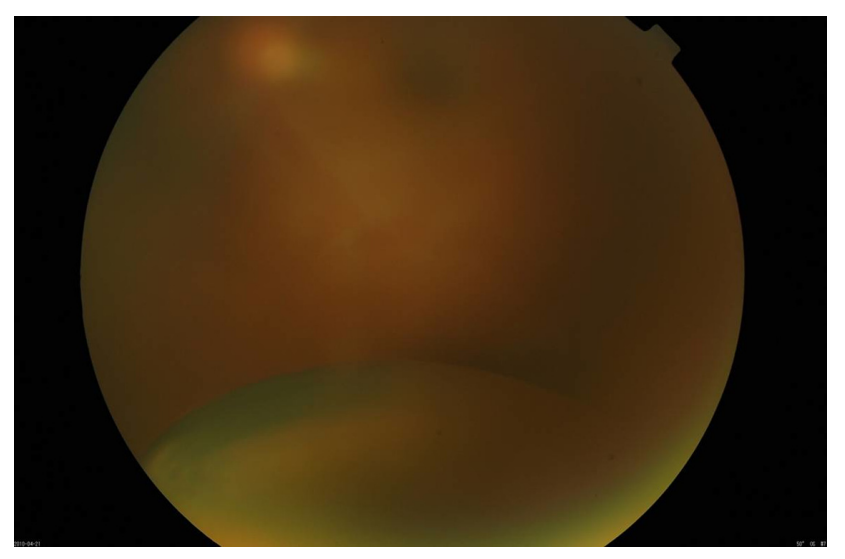

Figure 4 Preoperative ocular fundus examination of the left eye. The lens has been displaced into the vitreous cavity.

addition, when eye trauma occurs due to domestic violence, the damage to the victim tends to be very severe and usually requires surgical treatment. ${ }^{6,11,12}$

When lens dislocation occurs due to physical abuse, fractures of the lateral wall and roof of the left maxillary antrum in addition to secondary glaucoma are often observed. ${ }^{4}$ While it was fortunate that there were no other injuries in this patient, this situation is not always typical. Thus, when an ophthalmology patient is suspected of having been physically abused, full body examination needs to be performed in order to ensure there are no other serious problems.

In the present case, we were unable to perform a vitrectomy, because our hospital rules require that a patient be admitted prior to the procedure. In contrast, there are now new clinics that have begun performing vitrectomies on an outpatient basis. ${ }^{13}$ These types of clinics may prove to be very beneficial for those who might otherwise be too difficult to try and admit to a regular institution, such as subjects with senile dementia.

We believe that it is quite likely that our current case, who had been previously abused, will once again be subjected to a recurrence of this domestic violence due to these circumstances. In conclusion, when ophthalmologists examine older subjects, they may need to evaluate the living environment carefully and consider the possibility that elder abuse could potentially be the cause of any observed eye traumas in these types of patients.

\section{Disclosure}

The authors report no conflicts of interest in this work.

\section{References}

1. Ohtsuka R, Kikuchi K, Nonaka K, et al. Care-management process and factors in elder abuse. Japanese Journal of Social Welfare. 2011;51: 104-115.

2. Fitzpatrick MJ, Hamill SB. Elder abuse: Factors related to perceptions of severity and likelihood of reporting. J Elder Abuse Negl. 2011;23: $1-16$.

3. Collins KA, Sellars K. Vertebral artery laceration mimicking elder abuse. Am J Forensic Med Pathol. 2005;26:150-154.

4. Scothorn DM, Sporn A, Terry JE. Ectopia lentis secondary to physical abuse in a traumatized, elderly individual. J Am Optom Assoc. 1991;62: 630-633.

5. Oh J, Smiddy WE. Pars plana lensectomy combined with pars plana vitrectomy for dislocated cataract. J Cataract Refract Surg. 2010;36: 1189-1194.

6. Matsumoto Y. A case of bilateral posteriorly dislocated crystalline lens into the vitreous cavity at the same time due to domestic violence. Folia Japonica de Ophthalmologica Clinica. 2008;1:41-44.

7. Kunavisarut $P$, Intarated $C$, Pathanapitoon K. Bilateral traumatic anterior crystalline lens dislocation by water splash during Songkran festival: case report. J Med Assoc Thai. 2009;92:1544-1547.

8. Ryden MB. Aggressive behavior in persons with dementia who live in the community. Alzheimer Dis Assoc Disord. 1988;2:342-355.

9. Grafström M, Nordberg A, Winblad B. Abuse in the eye of the beholder. Report by family members about abuse of demented persons in home care. A total population-based study. Scand J Soc Med. 1993; 21:247-255.

10. Iwase H. Violence within the family: an examination of changing perspectives and terminology in Japan. Research Journal of Living Science. 2008;54:16-25.

11. Aoyama K, Shinzato E, Sugita I, et al. A case of severe eye injury by domestic violence. Jpn J Clin Ophthalmol. 2007;61:2061-2064.

12. Goldberg SH, McRill CM, Bruno CR, et al. Orbital fracture due to domestic violence: an epidemiologic study. Orbit. 2000;19: $143-154$.

13. Yoshizawa T, Shiratori A. Vitreous surgery on an outpatient basis for idiopathic macular holes. Jpn J Clin Ophthalmol. 2010;64: 695-698.
Clinical Ophthalmology

\section{Publish your work in this journal}

Clinical Ophthalmology is an international, peer-reviewed journal covering all subspecialties within ophthalmology. Key topics include: Optometry; Visual science; Pharmacology and drug therapy in eye diseases; Basic Sciences; Primary and Secondary eye care; Patient Safety and Quality of Care Improvements. This journal is indexed on

\section{Dovepress}

PubMed Central and CAS, and is the official journal of The Society of Clinical Ophthalmology (SCO). The manuscript management system is completely online and includes a very quick and fair peer-review system, which is all easy to use. Visit http://www.dovepress.com/ testimonials.php to read real quotes from published authors. 